\title{
Effect of Food Kinds on Developmental Stages and Fecundity of the Astigmatid Mites, Tyrophagus putrescentiae (Schrank) and Rhizoglyphus robini Claparede (Astigmata: Acaridae) \\ Yassin, E. M. A.; Enas M. K. Kassem and Rania H. Mahmoud \\ Plant Protection Research Institute, Agricultural Research Center, Dokki, Giza, Egypt
}

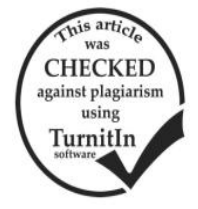

\section{ABSTRACT}

This investigation was conducted to study the different biological aspects of astigmatid mites, Tyrophagus putrescentiae (Schrank) and Rhizoglyphus robini Claparede (Astigmata:Acaridae) when fed on different food kinds i.e. pure white wheat flour, normal wheat flour, wheat germ, rice flour, maize flour and semolina at $25 \pm 2{ }^{\circ} \mathrm{C}$ and $75 \pm 5 \%$ R.H.. The results indicated that there were obvious differences between (incubation period, life cycle, longevity and life span) of both $T$. putrescentiae and $R$. robini and the different introduced food. The longest life span periods of $T$. putrescentiae male and female were noticed when the individuals fed on wheat flour, as recorded 41.61 and 50.9 days, respectively. However, the longest life span periods of $R$. robini were observed on maize flour and recorded 49.2 and 41.2 days for male and female indivduals, respectively. The food type's suitability clearly affected the number of deposited eggs by the adult female of both $T$. putrescentiae and $R$. robini and revealed highly significance between the feeding on wheat flour for the first mite and maize flour for the second one (the most suitable feeding sources for mites) than any other feeding types. The highest number of $T$. putrescentiae eggs was 40.2 eggs on wheat flour and the lowest number was recorded on wheat germ (27.8 eggs).However, the highest deposited number of $R$. robini eggs was noticed when adult female fed on maize flour (140.2 eggs), but the lowest number of laid eggs was found when the indivduals reared on wheat germ (70.4 eggs).

\section{INTRODUCTION}

A stored product constitutes a biological system with limited energy and is influenced by several abiotic and biotic factors. The nutritional value of wheat is extremely important as it takes an important place among the few crop species being extensively grown as staple food sources. The importance of wheat is mainly due to the fact that its seed can be ground into flour, semolina, etc., which form the basic ingredients of bread and other bakery products, as well as pastas, and thus it presents the main source of nutrients to the most of the world population (Sramkova et al., 2009).The wheat germ lies at one end of the grain. It is rich in proteins (25\%) and lipids (8-13\%).

The mineral level is also rather high $(4,5 \%)$. Wheat germ is available as a separate entity because it is_an important source of vitamin E. Wheat germ has only one half the glutamine and proline of flour, but the levels of alanine, arginine, asparagine, glycine, lysine and threonine are double (Cornell, 2003).Stored product mites form an important group among biotic factors infesting these materials. The relative humidity of the micro-environment as well as the temperature and food sources are the main ecological factors affecting the growth and development of different mites. Stored mites flourish in warm and damp environments where they feed on protein rich substance such as grain, fungi and other micro-organisms. Mites infested food products undergo a series of changes in their chemical composition and flour prepared from contaminated grains is more acidic, fusty smell and bitter taste. Mites of sub-order Acaridida (Astigmata) are known to infest a wide varity of stored materials throughout the world. These mites are a major cause of qualitative and quantitative losses to theses stored materials, Hughes (1976). Nutrition is one on the important factors which has a modifying effect on growth and life span of mites, the growth of mite population is directly related with the biological as well as physical factors operating the ecosystem. The stored product mites of the genera Tyrophagus oudemans and Rhizoglyphus (Claparede) (Acaridae) have been identified as pests of many crops and ornamentals in storage, in the greenhouse, and in the field.
T. putrescentiae and Rhizoglyphus robini Claparede are the most frequently found in stored food with relatively high fat and protein content, such as wheat and soy, flour, cheese, rye bread, herring meal, bacon, dried milk and various seeds (Duek et al. 2001; Zhang, 2003).The scope of this work was mainly dealing with the biological aspects of the astigmatid mites, T. putrescentiae and $R$. robini when fed on different kinds of food stored products at $25 \pm 2{ }^{\circ} \mathrm{C}$ and $75+5 \%$ R.H. .

\section{MATERIALS AND METHODS}

The astigmatid mites Tyrophagus putrescentiae and Rhizoglyphus robini (Acaridae: Astigmata) were reared on six different freshly materials i.e. pure wheat flour (white wheat flour), normal wheat flour (wheat flour), wheat germ, maize flour, rice flour and semolina) under constant laboratory conditions $\left(25 \pm 2{ }^{\circ} \mathrm{C}\right.$ and $70+5 \%$ R.H. $)$. The first mite was extracted from stored wheat bran and the second one was collected associated with onion bulbs (at Ashmoun region, El-Menuofia Governorate) by aiding of Modified Tullgren funnels. For preparing pure culture of tested mites, plastic cups of $(1.5 \mathrm{~cm}$ high $\times 2.5 \mathrm{~cm}$ diameter) were filled up to $0.5 \mathrm{~cm}$ with substrate of (plaster of Paris and activated charcoal in the rate of 8: 2, respectively). One adult female and male of each $T$. putrescentiae and $R$, robini were supplied with dry yeast as food and drops of water (to maintain suitable relative humidity) and incubated at $25^{\circ} \mathrm{C}$. For individual rearing, ten newly deposited eggs of each mite were transferred from the mother culture to newly rearing plastic cells contains the six previously mentioned tested food sources. Each newly hatched larva was supplied with food and kept till reaching maturity. Mites were examined twice a day. As soon as females emerged (on each rearing host), males were introduced for mating. Deposited eggs were collected during $12 \mathrm{~h}$ post-oviposition. Eggs were individually placed into newly cells with the aid of camel hair brush and incubated at the same conditions mentioned above. Fifteen eggs were used per each rearing material and observed every $12 \mathrm{~h}$ until hatching and mite become mature or died. At each rearing host, the incubation period, life cycle, longevity and life span of males and females and fecundity (total number of eggs laid per female) were calculated. All 
presented data were subjected to one way of variance (ANOVA) and means were separated by Duncan's multiple range test, (Duncan,1955).

\section{RESULTS AND DISCUSSION}

This study was conducted to throw some lights on the effect of some food stuffs; normal wheat flour (wheat flour), pure wheat flour (white wheat flour), maize flour, wheat germ, semolina and rice flour) on the main biological aspects of the acarid mites, $T$. putrescentiae and $R$. robini at $25 \pm 2{ }^{\circ} \mathrm{C}$ and $75 \pm 5 \%$ R.H.

Feeding behavior, mating, hatching and molting.

The acarid mites, T. putrescentiae and R. robini possesses a few teeth on the fixed digit chelicerae seems to be more adapted for cutting and biting a characteristic feature of fungivorous and granivorous or omnivorous mites (Woolley, 1988; Fan and Zhang, 2003). Mating is necessary for both mite $T$. putrescentiae and $R$. robini, and the females not deposited eggs without this process. The mating occurring immediately after emergence of adult female. After emergence of the adult male and female stages, mating process occurred immediately in which the male cling over the female dorsum with their opisthosoma opposite to each other, and firmly seizing the female with hind legs. Mating process lasted about 15-20 minutes. Eggs of $T$. putrescentiae and $R$. robini are ovoid, globular or elliptical. The eggs are whitish in color. Before incubation, the embryo grows gradually in size and hatched to whitish small larvae. During hatching the shell rupture through a longitudinal slit from which larvae crawls outside with its legs leaving the egg shell. The hatching process lasted about (20-30 minutes). The hatched larvae of both tested mites stayed inactive for a short time and then began its activity. Immature stages (larvae and nymphs) searched for a suitable place, then they stop movement and feeding, extending their forelegs forwards and the hind legs backwards. At the end of this period, moulting occurs.

\section{A- Tyrophagus putrescentiae 1.Incubation period:}

From the tabulated data in Table (1), indicated that the obvious difference between the incubation period of $T$. putrescentiae and different introduced food types. This period took the longest period when the individuals fed on wheat germ, (4.1 days) and decreased to record the shortest period (3.03 days) when the mite fed on wheat flour. The statistical analysis of obtained data indicated that L.S.D. for incubation periods at $0.05=0.379$.

\section{Life cycle:}

The influence of different food types on life cycle of $T$. putrescentiae male and female can be summarized in Table (1), which revealed that the mean periods were $10.21,10.04,10.8,11.42,11.8$ and 13.4 days when the male individuals fed on wheat flour, rice flour, pure wheat flour, semolina, maize flour and wheat germ, respectively. However, these periods changed to recorded 11.48, 11.84, $12.2,12.82,13.1$ and 13.9 days when the female indivduals of the mite fed on the same order of introduced food types, respectively. Statistical analysis of obtained data showed that L.S.D. at $0.05=0.314$ and 0.239 for males and females, respectively.

3. Longevity:

Concerning the adult longevity, Table (1), statistical analysis using L.S.D. at 0.05 level value pointe that the longevity of the resulted males and females was significantly differed when the mite $T$. putrescentiae fed on the different food types (L.S.D. $=0.619$ and 0.697 for males and females, respectively).The longevity period averaged $31.4,30.1,29.5,28.6,25.0$ and 22.4 days for males, changed to $39.42,38.6,36.5,33.9,26.9$ and 24.7 days when female indivduals fed on wheat flour, rice flour, pure wheat flour, semolina, maize flour and wheat germ, respectively.

\section{Life span:}

Accordingly, the life span of $T$. putrescentiae males and females also affected by feeding on different foods as shown in Table (1). The shortest period of life span resulted when the male indivduals fed on wheat germ and averaged 35.8 days, but the longest resulted life span was recorded when the female indivduals fed on wheat flour (50.9 days). (L.S.D. at $0.05=0.795$ and 0.814 for males and females, respectively.

Table 1. Duration of different stages of Tyrophagus putrescentiae fed on different diets at $25^{\circ} \mathrm{C}$ and $70 \% \mathrm{R} . \mathrm{H}$.

\begin{tabular}{|c|c|c|c|c|c|c|c|c|}
\hline \multirow{2}{*}{$\begin{array}{l}\text { Biological } \\
\text { stages }\end{array}$} & & \multicolumn{6}{|c|}{ Types of food } & \multirow{2}{*}{$\begin{array}{l}\text { L.S.D. at } \\
0.05\end{array}$} \\
\hline & & Wheat flour & Rice flour & Pure wheat flour & Semolina & Maize flour & Wheat germ & \\
\hline \multicolumn{2}{|l|}{ Incubation period } & $3.03 \pm 0.09$ & $3.04 \pm 0.12$ & $3.2 \pm 0.11$ & $3.42 \pm 0.12$ & $3.5 \pm 0.14$ & $4.1 \pm 0.16$ & 0.379 \\
\hline \multirow{2}{*}{ Life cycle } & o & $10.21 \pm 0.57$ & $10.04 \pm 0.48$ & $10.8 \pm 0.61$ & $11.42 \pm 0.49$ & $11 . \overline{8} \pm 0.6$ & $13 . \overline{4} \pm 0.42$ & 0.314 \\
\hline & 우 & $11.48 \pm 0.64$ & $11.84 \pm 0.58$ & $12.2 \pm 0.69$ & $12.82 \pm 0.76$ & $13.1 \pm 0.59$ & $13.9 \pm 0.95$ & 0.239 \\
\hline \multirow{2}{*}{ Longevity } & $\pi$ & $31.4 \pm 1.3$ & $30.1 \pm 1.7$ & $29.5 \pm 1.6$ & $28.6 \pm 1.4$ & $25.0 \pm 1.0$ & $22.4 \pm 1.4$ & 0.619 \\
\hline & 우 & $39.42+1.1$ & $38.6+1.19$ & $36.5+0.84$ & $33.9 \pm 0.64$ & $26.9 \pm 0.76$ & $24.7 \pm 0.55$ & 0.697 \\
\hline \multirow{2}{*}{ Life span } & $\overline{0}$ & $41.61+1.12$ & $40.5 \pm 1.57$ & $40.3 \pm 1.9$ & $40.02 \pm 1.14$ & $36.8 \pm 1.5$ & $35.8 \pm 1.32$ & 0.795 \\
\hline & q & $50.9 \pm 1.47$ & $50.7 \pm 1.34$ & $48.7 \pm 1.6$ & $46.72 \pm 1.44$ & $40.0 \pm 1.67$ & $38.6 \pm 0.86$ & 0.814 \\
\hline
\end{tabular}

\pm S.D.= Standard deviation. $\quad$ L.S.D. $=$ Least significant difference

\section{Pre-oviposition, oviposition and postoviposition} periods:

From the tabulated data in Table (2), cleared that the pre-oviposition period of $T$. putrescentiae was slightly affected by the type of used food.

Accordingly, this period was 2.1, 2.2, 2.22, 2.26, 2.1 and 1.78 days when the mite females fed on wheat flour, rice flour, pure wheat flour, semolina, maize flour and wheat germ, respectively. L.S.D. at $0.05=0.247$. On the other hand, the average duration of $T$. putrescentiae oviposition period lasted 34.92, 33.86, 32.17, 29.24, 22.4 and 21.0 days when the mite reared on the same diets, respectively (L.S.D. at $0.05=0.281$ ). However, Data presented in Table (2) showed slightly differences in postoviposition period, L.S.D. at $0.05=0.153$. 
Table 2. Effect of different diets on the longevity and fecundity of $T$. putrescentiae female at $25 \pm 2^{\circ} \mathrm{C}$ and $75+5 \% \mathrm{R} . \mathrm{H}$.

\begin{tabular}{lccccccc}
\hline \multirow{2}{*}{ Stages } & \multicolumn{7}{c}{ Types of food } \\
\cline { 2 - 7 } & $\begin{array}{c}\text { Wheat } \\
\text { flour }\end{array}$ & $\begin{array}{c}\text { Rice } \\
\text { flour }\end{array}$ & $\begin{array}{c}\text { Pure wheat } \\
\text { flour }\end{array}$ & Semolina & $\begin{array}{c}\text { Maize } \\
\text { flour }\end{array}$ & $\begin{array}{c}\text { Wheat } \\
\text { germ }\end{array}$ & $\begin{array}{c}\text { L.S.D. } \\
\text { at 0.05 }\end{array}$ \\
\hline Preoviposition period & $2.1 \pm 0.08$ & $2.2 \pm 0.16$ & $2.22 \pm 0.17$ & $2.26 \pm 0.14$ & $2.1 \pm 0.5$ & $1.78 \pm 0.22$ & 0.247 \\
Oviposition period & $34.92 \pm 0.62$ & $33.86 \pm 0.8$ & $32.17 \pm 0.48$ & $29.24 \pm 0.33$ & $22.4 \pm 0.42$ & $21.0 \pm 0.5$ & 0.281 \\
Postoviposition period & $2.4 \pm 0.24$ & $2.54 \pm 0.3$ & $2.11 \pm 0.09$ & $2.4 \pm 0.37$ & $2.4 \pm 0.6$ & $2.11 \pm 0.51$ & 0.153 \\
Fecundity & $40.2 \pm 1.4$ & $39.0 \pm 1.8$ & $36.8 \pm 1.6$ & $34.0 \pm 1.5$ & $31.4 \pm 0.64$ & $27.8 \pm 0.7$ & 1.104 \\
\hline
\end{tabular}

\pm S.D. $=$ Standard deviation. $\quad$ L.S.D. $=$ Least significant difference

\section{Fecundity:}

The food type's suitability clearly affected the number of deposited eggs by the adult female of $T$. putrescentiae and revealed highly significance between the feeding on wheat flour and rice flour (the most suitable feeding sources for mite) than any other feeding types (L.S.D. at 0.05 level $=1.014$ ). The highest number of eggs was 40.2 eggs on wheat flour, but the lowest number was recorded on wheat germ (27.8 eggs). The current study (Table 3) indicated that the different biological aspects of $T$. putrescentiae were highly affected in both sexes (male and female) when the different foods were used. The statistical analysis of data showed that L.S. D. at $0.05=$ 0.052 and 0.10 in case of incubation period for the effect of sex and diet on this period, respectively.

Table 3. Effect of different factors (sex and diet) on the biological aspects of $T$. putrescentiae at $25 \pm 2^{\circ} \mathrm{C}$ and $75+5 \%$ R.H.

\begin{tabular}{|c|c|c|c|c|c|}
\hline \multirow{2}{*}{$\begin{array}{l}\text { Biological } \\
\text { aspect }\end{array}$} & \multirow[t]{2}{*}{ Source } & \multirow[t]{2}{*}{$\mathbf{F}$} & \multirow[t]{2}{*}{$\mathbf{P}$} & \multicolumn{2}{|c|}{$\begin{array}{l}\text { L.S.D. at } \\
\text { 0.05 level }\end{array}$} \\
\hline & & & & Sex & Diet \\
\hline \multirow{3}{*}{$\begin{array}{l}\text { Incubation } \\
\text { period }\end{array}$} & Sex & 44.00 & $0.000^{* * *}$ & \multirow{3}{*}{0.052} & \multirow{3}{*}{0.10} \\
\hline & Diet & 115.56 & $0.000^{* * *}$ & & \\
\hline & Int. sex $\mathrm{x}$ diet & 4.68 & $0.0124 *$ & & \\
\hline \multirow{3}{*}{ Life cycle } & Sex & 165.39 & $0.000 * * *$ & \multirow{3}{*}{0.216} & \multirow{3}{*}{0.318} \\
\hline & Diet & 8671.33 & $0.000 * * *$ & & \\
\hline & Int. sex $x$ diet & 3.24 & $0.0349 *$ & & \\
\hline \multirow{3}{*}{ Longevity } & Sex & 1233.11 & $0.000 * * *$ & \multirow{3}{*}{0.498} & \multirow{3}{*}{0.577} \\
\hline & Diet & 555.0 & $0.000 * * *$ & & \\
\hline & Int. sex $x$ diet & 6.44 & $0.0019^{* *}$ & & \\
\hline \multirow{3}{*}{ Life span } & Sex & 1444.25 & $0.000 * * *$ & \multirow{3}{*}{0.541} & \multirow{3}{*}{0.722} \\
\hline & Diet & 86.64 & $0.000 * * *$ & & \\
\hline & Int. sex $x$ diet & 9.33 & $0.0000 * * *$ & & \\
\hline
\end{tabular}

However, L.S. D. was 0.216 \& 0.318; 0.498 \& 0.577 and $0.541 \& 0.722$ in case of life cycle, longevity and life span, respectively. Although $T$. putrescentiae has previously been described as saprophagous species (Hughes, 1976), their attraction to, and successful completion of life cycles feeding exclusively on maize flour, rice flour, semolina, wheat flour, pure wheat flour and wheat germ, suggests frequent utilization of this food resources under natural conditions.

The results obtained by Chmielewski (1999) showed that bruised buckwheat is accepted as food by the mould mite, T. putrescentiae which allows completing its development and multiplication. The main life cycle 16.9 days and the high fecundity and fertility of this mite species indicated that bruised buckwheat seems to be most favorable medium for rearing this acarid mite. Also, Sarwar et al., (2010) mentioned that the assessment of macronutrients in soybean, maize, and wheat flours showed that wheat had more carbohydrate and ash but reduced protein and fat contents and merits as leading compound in supporting higher $T$. putrescentiae populations. The authors added that egg, larval, protonymphal, and deutonymphal stages of $T$. putrescentiae that fed on wheat had faster development compared to those fed on maize and soybean. The female longevity averaged $34.1,27.0$, and 40.8 days and male longevity was $23.5,18.7$, and 28.7 days when raised on maize, soybean, and wheat, respectively. Similar results were obtained by Abd El-Khalik (2013) who noticed that the life span of $T$. putrescentiae, affected by the types of food, as the female life span averaged 50.1, 47.2, 40.3 and 39.1 days when the mites fed on wheat flour, milk powder, granular feed and fish powder, respectively at $25^{\circ} \mathrm{C}$ and 75 $\%$ R.H. She also noticed that the feeding on different source of food affected significantly on the fecundity of T.putrescentiae. The highest deposited number of eggs was noticed when the female fed on wheat flour (39.2 eggs), but the lowest number recorded when the mite fed on fish powder (28.0 eggs). The female deposited 34.2 eggs on milk powder and 30.0 eggs on granular chicken feed.

\section{B- Rhizoglyphus robini \\ 1. Incubation period:}

As shown in Table (4), the obtained data cleared that there were not significant differences for influence of different food kinds on egg incubation period of the acaridid mite, $R$. robini. These periods ranged from 3.31 and 3.62 days when the mite fed on maize flour and wheat germ, respectively. (L.S.D. at $0.05=0.45$ ).

Table 4. Duration of different stages of Rhizoglyphus robini fed on different diets at different temperatures at $25^{\circ} \mathrm{C}$ and $70 \%$ R.H.

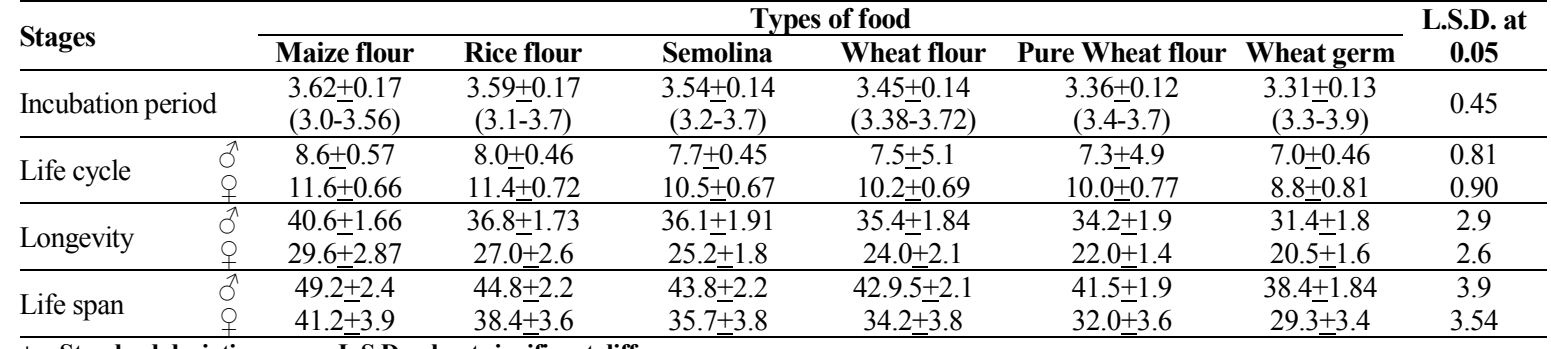




\section{Life cycle:}

The tabulated data in Table (4) indicated that the female life cycle of $R$. robini lived longer than male indivduals under tested conditions of different kinds of food. The obtained results revealed that obviously significant differences in the life cycle. The life cycle averaged $8.6,8.0,7.7,7.5,7.3$ and 7.0 days for male indivduals, changed to recorded 11.6, 11.4, 10.5, 10.2, 10.0 and 8.8 days for female indivduals when fed on maize flour, rice flour, semolina, wheat flour, pure wheat flour and wheat germ, respectively, Table (4). These results clearly indicated that maize flour was the most suitable diet for life cycle of $R$. robini.

\section{Longevity:}

As shown in Table (4), male adulthood period of $R$. robini duarted the longest periods than female indivduals, as recorded 40.6, 36.8, 36.1, 35.4, 34.2 and 31.4 days on maize flour, rice flour, semolina, wheat flour, pure wheat flour and wheat germ, respectively, changed to 29.6, 27.0, 25.2, 24.0, 22.0, and 20.5 days for female indivduals fed on the same previously mentioned diets, respectively. The statistical analysis of data showed that L.S.D. at 0.05 level $=2.9$ and 2.6 for males and females, , respectively.

\section{Life span:}

Accordingly, the female and male life span of the acaridid mite, $R$. robini, was different significantly differed according to the kind of used food, Table (4). The obtained results revealed that the longest life span was recorded for male indivduals fed on maize flour (49.2 days) and the shortest period was found when the females reared on wheat germ (29.3 days). L.S.D. at $0.05=3.9$ for males and 3.54 for females, respectively.

\section{Pre-oviposition, oviposition and post-oviposition} periods:

The influence of different diets on female preoviposition period of $R$. robini, Table (5) revealed that this period lasted 4.6, 4.2, 3.9, 3.6, 3.4 and 3.2 days when the indivduals fed on maize flour, rice flour, semolina, wheat flour, pure wheat flour and wheat germ, respectively. L.S.D. at $0.05=1.64$. The same obtained data indicated that the kind of introduced food to $R$. robini was significantly affected on the oviposition period of this astigmatid mite. The longest period noticed when the mites fed maize flour and averaged 18.5 days, which decreased to recorded the shortest period on wheat germ (13.5 days) with L.S.D. at 0.05 level $=2.68$. The results in Table (5) showed that there were significant differences between the postoviposition period of $R$. robini fed on different diets which averaged 6.5, 5.7, 5.2, 4.8, 4.1 and 3.8 days when females fed on maize flour, rice flour, semolina, wheat flour, pure wheat flour and wheat germ, respectively. L.S.D. at $0.05=1.39$

\section{Female fecundity:}

The current study indicated that the different diets affected significantly on the number of deposited eggs by female of $R$. robini. The highest number of eggs recorded in Table (5) was laid when adult female mite fed on maize flour (140.2 eggs), but the lowest number of resulted eggs was demonstrated when the mite indivduals reared on wheat germ (70.4 eggs). The statistical analysis of obtained data observed that L.S.D. at 0.05 level was 13.65.

Table 5. Effect of different diets on the longevity and fecundity of Rhizoglyphus robini female at $25 \pm 2^{\circ} \mathrm{C}$ and $75 \pm 5 \%$ R.H.

\begin{tabular}{lccccccc}
\hline \multirow{2}{*}{ Stages } & \multicolumn{9}{c}{ Types of food } & L.S.D. at \\
\cline { 2 - 6 } & Maize flour & Rice flour & Semolina & Wheat flour & Pure wheat flour Wheat germ & 0.05 level \\
\hline Preoviposition period & $4.6 \pm 0.45$ & $4.2 \pm 0.34$ & $3.9 \pm 0.27$ & $3.6 \pm 0.21$ & $3.4 \pm 0.33$ & $3.2 \pm 0.36$ & 1.64 \\
Oviposition period & $18.5 \pm 0.78$ & $17.1 \pm 0.55$ & $16.1 \pm 0.43$ & $15.6 \pm 0.4$ & $14.5 \pm 0.38$ & $13.5 \pm 0.34$ & 2.68 \\
Postoviposition period & $6.5 \pm 0.43$ & $5.7 \pm 0.41$ & $5.2 \pm 0.46$ & $4.8 \pm 0.4$ & $4.1 \pm 0.38$ & $3.8 \pm 0.41$ & 1.39 \\
Fecundity & $140.2 \pm 6.5$ & $122.5 \pm 5.41$ & $110.6 \pm 5.8$ & $85.6 \pm 4.2$ & $75.6 \pm 4.2$ & $70.4 \pm 3.6$ & 13.65 \\
\hline
\end{tabular}

$\pm=$ Standard deviation $\quad$ L.S.D. $=$ least significant differences

Generally, the best host for feeding the astigmatid mite, $R$. robini was maize flour, but the lowest favorable one was wheat germ. The obtained results in Table (6) explained the relation between the mite sex (male and female), tested diets and the different biological aspects of $R$. echinopus. The results denoting that the relations were highly significant. The current study indicated that all of the selected food products have already been found suitable for extent for the tested mite species survival and development. Out of the tested diets for rearing the mites the most attractive food was maize flour, but the lowest one is wheat germ. Although wheat germ was less suitable than other food types, the mites positively reared and reproduced on this diet. Similar results were obtained by Qu et al., (2018) who noticed that the developmental time for the immature stages of $R$. robini was significantly affected by fungal species, ranging from $9.45 \pm 1.83$ days reared on the Lentinula edodes (Berk.) at $31^{\circ} \mathrm{C}$ to $26.39 \pm$ 2.10 days reared on Agaricus bisporus Lange at $15^{\circ} \mathrm{C}$. On the other hand, Raut and Sarkar (1991) found this mite required $25.8,18.3,15.6$ and 18.0 days reared on semi- decomposed potato slices to complete its life-cycle when maintained at $15,20,25,30^{\circ} \mathrm{C}$.

Table 6. Effect of different factors (sex and diet) on the biological aspects of Rhizoglyphus robini at 25 $\pm 2^{\circ} \mathrm{C}$ and $\mathbf{7 5} \underline{+5 \%}$ R.H.

\begin{tabular}{lccccc}
\hline \multirow{2}{*}{$\begin{array}{l}\text { Biological } \\
\text { aspect }\end{array}$} & Source & F & P & \multicolumn{2}{c}{$\begin{array}{c}\text { L.S.D. at 0.05 } \\
\text { level }\end{array}$} \\
\cline { 3 - 6 } & & & & Sex & Sex \\
\hline Incubation & Sex & 51.00 & $0.000^{* * *}$ & & \\
period & Diet & 92.6 & $0.000^{* * *}$ & 0.042 & 0.19 \\
& Int. sex x diet & 4.33 & $0.0321 *$ & & \\
\hline \multirow{3}{*}{ Life cycle } & Sex & 136.54 & $0.000^{* * *}$ & & \\
& Diet & 7452.36 & $0.000^{* * *}$ & 0.301 & 0.287 \\
& Int. sex x diet & 5.24 & $0.0514^{*}$ & & \\
\hline \multirow{5}{*}{ Longevity } & Sex & 1245.33 & $0.000^{* * *}$ & & \\
& Diet & 651.0 & $0.000^{* * *}$ & 0.455 & 0.621 \\
& Int. sex x diet & 7.22 & $0.0026^{* *}$ & & \\
\hline \multirow{5}{*}{ Life span } & Sex & 1243.22 & $0.000^{* * *}$ & & \\
& Diet & 85.64 & $0.000^{* * *}$ & 0.419 & 0.805 \\
& Int. sex x diet & 4.673 & $0.0000^{* * *}$ & & \\
\hline$*$ significant & $* *=$ highly significant & $* * *=$ very highly significant
\end{tabular}




\section{REFERENCES}

Abd El-Khalik, A. R. 2013. Studies on the effect of certain mites on some food products. M. Sc. Thesis, Fac. Sci. El-Menofia Univ., 104 pp.

Chmielewski, W.1999.Acceptance of buckwheat grain as a food by Tyrophagus putrescentiae (Schrank) (Acari: Acaridae). Fagopyrum, 16:95-97.

Cornell, H. 2003. Bread Making: Improving Quality. Woodhead Publishing, Cambridge

Duek, L.; Kaufman, G.; Palevsky, E. and Bericevsky, I. 2001.Mites in fungal cultures. Mycoses, 44 (910):390-394.

Duncan, D. B. 1955.Multiple range and multiple F. test. Biometrics, 11: 1-42.

Fan, Q. and Zhang, Z. 2003. Rhizoglyphus echinopus and Rhizoglyphus robini (Acari: Acaridae) from Australia and New Zealand: identification, host plants and geographical distribution. Systematic \& Applied Acarology, Special Publications, 16, 1-16.

Hughes, A. M.1976. The mites of stored food products and houses. Tech. Bull., Min. Agric. and Fisheries in London, 63: 105 - 110.

Qu, S.; Luo, X. and Ma, L. 2018. Effect of fungal species on development and reproductive traits of the fungal-feeding mite Rhizoglyphus robini (Astigmata: Acaridae). J. Econ. Entomol., 111 $(1,9): 154-158$.
Raut, S.K., and Sarkar, R.. 1991. The influence of temperature on the life cycle of Rhizoglyphus robini Claparede (Acari: Acaridae). Int. J. Acarol. 17: 145-148.

Sarwar, M; Xuenong, X. and Kongming, W.2010. Effects of different flour on the biology of the prey Tyrophagus putrescentiae (Schrank) (Acarina: Acaridae) and the predator Neoseiulus pseudolongispinosus (Xin, Liang and $\mathrm{Ke}$ ) (Acari: Phytoseiidae). International Journal of Acarology, 36 (5): 363-369.

Sramková, Z.; Gregova, E. and Sturdik, E. 2009. Chemical composition and nutritional quality of wheat grain. Acta Chimica Slovaca, 2, (1): 115 138.

Woolley, T.A.1988.Acarology- Mites and human welfare.Jhon Wiley and Sons, New York, pp. 8693.

Zhang, Z. 2003. Mites of greenhouses, identification, biology and control. CABi Publishing, 244 pp.

\section{تأثير نوع الغذاء على أطوار النمو وخصوبة الاكاروسات عديمة الثغز

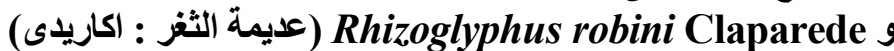 عصام محمد عبد السلام ياسين ، إيناس مصطفى قطب قاسم و و ر رانيا حسن محمود

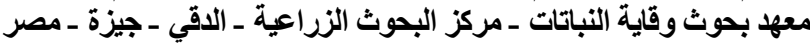

أجريت هذه الدر اسة لمعرفة المظاهر البيولوجية المختلفة (فترة حضانة البيض ودورة الحياة وفترة حياة الأفراد البالغة والفترة الكلية لحياة

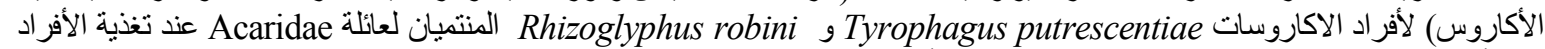

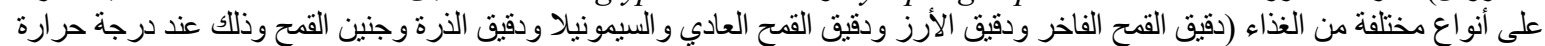

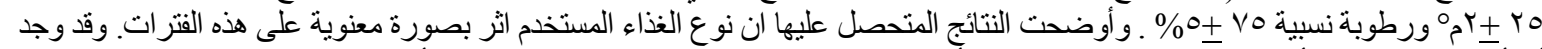

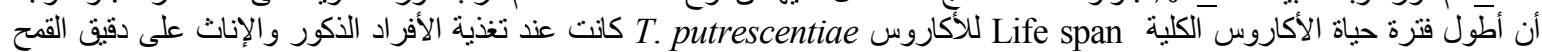

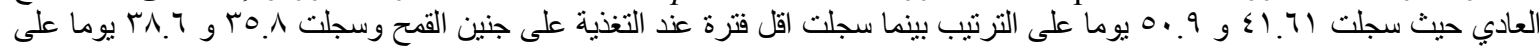

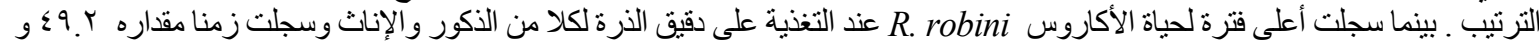

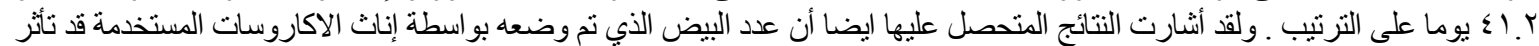

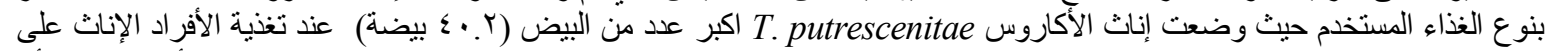

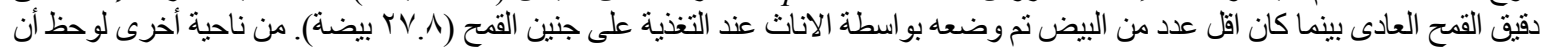

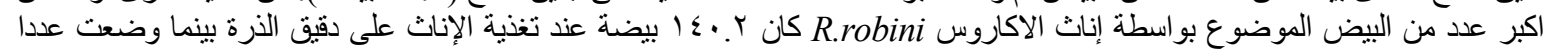

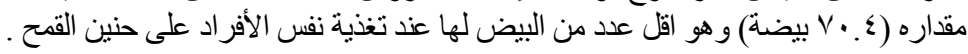

